\title{
LA FIESTA VERDADERA: :UNA REALI- ZACIÓN FELIZ EN EL TEATRO? LUCES Y SOMBRAS DE LOS ENCUENTROS DE TEATRO COMUNITARIO EN MÉXICO
}

\author{
ELIZABETH ARAIZA HERNÁNDEZ
}

\section{RESUMEN}

A partir de la restitución al teatro en su función primordial de religar a los seres humanos y proveerles de una experiencia ritual y festiva, se lleva a cabo la descripción y análisis de diversos encuentros convocados por la asociación de Teatro Comunitario en México diferenciándolo del conjunto del teatro popular, universitario, rural, indígena y campesino.

La interpretación que aquí se presenta se apoya en un trabajo de observación directa llevado a cabo durante varios años (1992-2000), en diversos poblados, en varias situaciones de representación y en numerosas conversaciones con las personas que participan en estos eventos: organizadores, actores, espectadores y habitantes de las comunidades donde se ha realizado.

\section{THE REAL FEAST: A HAPPY DRAMA PRODUCTION? LIGHTS AND SHADOWS IN COMMUNITY THEATRE EVENTS IN MEXICO}

\section{ABSTRACT}

Using the return to the primordial function of theatre as a way to bring people together and provide them with a ritualistic and festive experience as a basis, a description and analysis of different events beld by the Community Theatre Association in Mexico are given, differentiating it from popular, academic, rural, indigenous and peasant theatre.

The interpretation given bere is based on direct observation work carried out over many years (1992-2000) in different locations, with varied representational situations and numerous conversations with those taking part in the events: organisers, actors, spectators and inhabitants of the communities where the performance was beld.

La noción de fiesta ha guiado numerosas experiencias teatrales, sobre todo aquellas que se proclaman populares o alternativas, experimentales o no-oficiales. Dos de los imperativos de este tipo de teatro han con- ducido a mistificar una cierta concepción de fiesta, la de la «fiesta verdadera», la fiesta patronal. El primer imperativo, de algún modo presente en toda experiencia teatral, es el de abarcar un público amplio y diverso.

\section{Elizabeth Araiza Hernández}

Investigadora docente en el Departamento de Sociología de la Universidad de Perpignan (Francia). Miembro del laboratorio de Investigaciones en Etnoescenología de la Maison des Sciences de l'Homme. Paris-Nord. Recibió una formación disciplinaria en Etnología en la Escuela Nacional de Antropología e Historia de México, donde impartió además cursos de 1991 a 1993. Su trabajo se sitúa en la intersección de varias disciplinas: antropología del arte, antropología del ritual, antropología performativa (performance studies), estudios teatrales, socio-antropología del cuerpo y etnoescenología. Se ha dedicado al estudio del teatro indígena contemporáneo a partir del vínculo que éste establece con otras formas de representación, principalmente el ritual, el juego, el trabajo y los mitos. Doctorada en la Universidad de París 8, su tesis Sous le signe de l'entre deux: anthropologie du théâtre amérindien au Mexique está en vías de publicación (Presses Universitaires de Bordeaux); ha publicado, además, numerosos artículos sobre este tema y sobre los problemas metodológicos de la antropología del teatro.
La fiesta verdadera: zuna realización feliz en el teatro? Luces y sombras de los encuentros de teatro comunitario en México ELIZABETH ARAIZA HERNANDEZ 


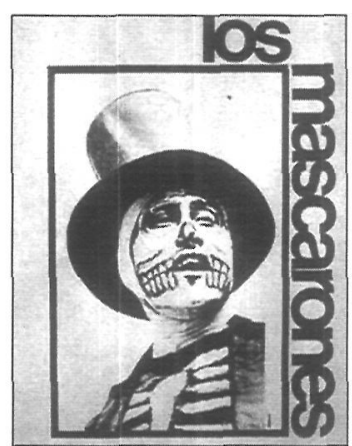

Cartel anunciador de Las calaveras de Posada. Grupo Mascarones.

1

Henri Gouhier, L'essence du théâtre, París, Aubier-Montaigne, «Présence et pensée», núm. 11, 1968, pág. 259. La traducción de todas las citas que aparecen en este texto y que originalmente fueron publicadas en francés, es mía.

2

Para obtener más detalles sobre la fiesta de Tlaltenango en Cuernavaca, ver Héctor Rosales Ayala, Tlaltenango: las transformaciones del sentido de una fiesta popular, México, UNAM-CRIM, 1988; sobre el grupo Cultural Mascarones y el teatro del grupo Zero, ver Donald Frischman, El nuevo teatro popular en México, México, CITRU-INBA, 1990; y, sobre el teatro relacionado con la Teología de la Liberación, ver Adam Versényi, El teatro en América Latina, Nueva York, Cambridge University Press, 1996.

La fiesta verdadera: $\dot{\text { una reali- }}$ zación feliz en el teatro? Luces y sombras de los encuentros de teatro comunitario en México

ELIZABETH

ARAIZA HERNÁNDEZ
El segundo es el de un regreso a los orígenes rituales y festivos del teatro. Un regreso a los orígenes implica, desde esta óptica, restituir al teatro su función primordial que es la de religar a las personas, proporcionarles una experiencia ritual y festiva. Para conjurar el vacío, el no-ser que amenaza a cada momento toda representación teatral, se acude con insistencia a la fiesta. Es así porque «la representación dirigida a una sola persona constituye una aberración, [porque] el vacío introduce en el teatro un principio de no-ser que compromete su operación decisiva» ${ }^{1}$. Vistas así las cosas, resulta que la participación masiva, unánime y entusiasta que genera la fiesta suscita al mismo tiempo una comunión entre actores y espectadores, quedando la frontera que los separa, en condiciones nofestivas, por completo abolida. Todo sucede como si la convergencia de los cuerpos fuera equivalente a una convergencia de las creencias y de las emociones, como si estar juntos fuera lo mismo que estar unidos.

\section{LAS ESTRATEGIAS DEL TEATRO CO- MUNITARIO PARA REPRODUCIR LA FIESTA}

Si se ponen en perspectiva los encuentros que cada año convoca la asociación civil u otras agrupaciones de teatro comunitario en México, se podrá constatar la existencia de tres estrategias principales tendientes a reproducir la fiesta. La primera consiste en integrar obras de teatro en la fiesta, o bien introducir un festival teatral en el marco general de la fiesta. La segunda consiste en utilizar los sistemas de organización social que rigen la fiesta (gremios, sistema de cargos) para constituir y dinamizar el proceso teatral: conformación del grupo, regularidad en la creación, la difusión, la recepción. La tercera estrategia consiste en investir el encuentro teatral o el festival de teatro con los signos característicos de la fiesta (objetos simbólicos, acciones corporales, discursos). Desde esta perspectiva se evidencia que, en el Teatro Comunitario, las dos primeras estrategias continúan en estado de proyecto ya que no han logrado desplegarse como prácticas sistemáticas y permanentes. Desde su emergencia como conjunto asociativo, el teatro comunitario ha buscado con insistencia una integración permanente del teatro en el marco de las fiestas locales, privilegiadamente en la fiesta patronal, de tal manera que la obra teatral se convierta en un elemento constitutivo de las actividades festivas, al mismo título que por ejemplo, la procesión, la misa, la quema del castillo y de los toritos, la danza tradicional, el «jaripeo» o la corrida de toros.

Hasta donde he logrado indagar, son escasos en México los grupos teatrales que han logrado una incorporación orgánica, esto es, sistemática y permanente, de sus producciones artísticas en la fiesta patronal. El caso del Grupo Cultural Mascarones parece más representativo de una excepción que de una regla. La fiesta dedicada a la Virgen de los Remedios, tutelar de Cuernavaca, incluye desde los años 1970 un programa cultural con obras teatrales ${ }^{2}$. Si un proyecto de esta naturaleza se hizo posible, es gracias a la regularidad con que se presentan las obras teatrales y a la presencia constante del Grupo Cultural Mascarones en el barrio. Así, una de las expectativas de los feligreses, de los visitantes y del público en general al asistir a la fiesta es presenciar las obras de teatro de este grupo. Esta iniciativa resulta tanto más sorprendente cuanto el contenido de las obras teatrales no sólo no corresponde con los contenidos generales de la fiesta sino que incluso parece contradecirlos. Se trata, en efecto, de obras explícitamente contestatarias de crítica social y política. Los contenidos deliberadamente subversivos del teatro no son impedimento para su integración en el marco de la fiesta, cuyos contenidos, en apariencia, reafirman y preservan un orden social y religioso. En el fondo, los contenidos mismos de la fiesta tradicional religiosa fueron trastocados, en esta misma época en que inicia el teatro, gracias a la presencia en Tlaltenango de militantes o simpatizantes de la Teología de la Liberación. No sólo el teatro obtiene un beneficio de esta situación, logrando atraer para sí un público multitudinario y entusiasta, sino que también la fiesta sale ganando con el carácter peculiar que éste le imprime.

La segunda estrategia no se centra tanto en la estructura de la fiesta como en los sistemas de organización social que la hacen posible, esto es, los gremios, el sistema de cargos, las asociaciones religiosas. La atención se enfoca más precisamente en el sistema de cargos, que rige la mayoría de las fiestas patronales y los sistemas rituales en el medio indígena. Resulta bastante revelador el hecho de que, después de varias tentativas, se lograra que en 1998 la VII Fiesta Estatal de Teatro Comunitario, celebrada en San Juan Tabàa, fuera organizada por el sistema de cargos de este pueblo zapoteco situado en la sierra de Oaxaca. Se 
trata, sin embargo, de una experiencia que se produjo una sola vez en la historia de esta asociación. Desde esta lógica de razonamiento resulta que, si cada una de las etapas del proceso teatral es regida por el sistema de cargos, se puede garantizar con ello una integración permanente en la fiesta $y$, al mismo tiempo, una continuidad del grupo teatral.

A pesar de la influencia tan grande que ejercen este tipo de experiencias, en que la organización de la actividad teatral queda regida por el sistema de cargos, éstas resultan ser más bien escasas. Un caso relevante a este respecto es el de San Miguel Cajonos, pueblo zapoteco situado en las montañas del estado de Oaxaca. Si el teatro es parte constitutiva del sistema festivo de este pueblo, se debe a un largo proceso cuyo inicio remonta a los años 1920. La actividad teatral no sólo ocupa un lugar importante en la fiesta principal sino que además cumple una función ritual, es iniciación al sistema de cargos ${ }^{3}$. Cabe precisar que uno de los requisitos para ocupar el primero de los cargos de este sistema (el de topil) es que los jóvenes aspirantes se ejerciten como actores en, al menos, una de las obras teatrales que se presentan durante la fiesta. El sentido ritual aquí no apela tanto a una creencia o a un estado de espiritualidad o de emoción como a una dimensión performativa, pragmática. Es la práctica ritual y festiva y no la creencia lo que marca la pertenencia del individuo a este pueblo y a este grupo étnico. Para ser considerado miembro de esta comunidad zapoteca, el individuo tiene que ocupar un cargo en dicho sistema y, para acceder a éste, se necesita haber atravesado el umbral marcado por la práctica teatral. Con su desempeño en el teatro, con su interpretación de un personaje, los jóvenes sanmigueleños están mostrando ser capaces de ocupar un cargo y estar listos para hacerlo. Se trata sin duda de un caso que los miembros de la asociación de teatro comunitario han erigido en modelo, sin que logren hasta ahora desplegarlo de modo regular.

La tercera, en cambio, es la estrategia que se aplica con mayor regularidad en los encuentros de Teatro Comunitario. En las páginas que siguen, presento una descripción del modo concreto en que se lleva a cabo. En un segundo momento intentaré identificar las razones por las cuales el ideal de fiesta que esta asociación transmite no se materializa en la práctica. Esto es, me propongo aportar elementos de reflexión para comprender por qué en estos encuentros no hay una realización feliz de la fiesta ${ }^{4}$.
Lo anotado hasta ahora exige una serie de precisiones. En primer lugar, resulta claro que, si se comparte la noción vaga e imprecisa de teatro comunitario con los miembros de la asociación que lleva este apelativo, se afirmará que en éste sí hay una realización feliz de la fiesta. Los casos que acabo de comentar (Grupo Cultural Mascarones y Teatro de San Miguel Cajonos) vendrían a corroborar tal afirmación, pues inevitablemente se les consideraría como parte del teatro comunitario, es decir, dentro de una gama enormemente amplia y diversa de grupos cuyo único signo distintivo es el de ser un teatro popular, universitario, campesino o indígena. Pero si se delimita el teatro comunitario a aquellas experiencias que deliberadamente se inscriben en esta asociación civil o que se autodefinen como tal, se concederá que en éstas impera en general una realización no feliz de la fiesta. Si se parte del principio que cualquier experiencia teatral puede ser considerada como teatro comunitario, no se llega demasiado lejos porque entonces ninguna lo es verdaderamente. La descripción y la interpretación que a continuación expongo concierne los encuentros que convoca la asociación de teatro comunitario y no el conjunto del teatro popular, universitario, rural, indígena o campesino.

En segundo lugar, cabe precisar el cuadro interpretativo. Cuando se trata de interrogar la realización feliz o no feliz de la fiesta se corre el riesgo de proyectar la fiesta anhelada sobre la fiesta vivida, la noción que se tiene de antemano sobre lo observado. La dificultad se hace mas grande todavía al no poder recurrir a una definición que pueda aplicarse a todos los casos. No disponemos en efecto de una teoría unificada o una concepción con validez general. Ante esta dificultad, las interpretaciones antropológicas y sociológicas de la fiesta buscan salir ya sea por la puerta del universalismo o bien por la del relativismo. La primera encuentra en la obra de Callois ${ }^{5}$ los fundamentos para postular una universalidad de la fiesta, independientemente de los aspectos que pueda adquirir en contextos locales. La concepción de Caillois, de algún modo dominante en los estudios de la fiesta, enfatiza los aspectos de exuberancia, exceso, dilapidación, alegría suprema, desorden y subversión que se supone están presentes en toda fiesta. Según esta concepción, habría que restringir este término a aquellas acciones «que comprometen a la sociedad entera, y que implican una efervescencia, una exaltación que se consume en gritos y gestos, que incitan
Véase Elizabeth Araiza Hernández, Sous le signe de "l'entre deux » Anthropologie du théâtre amérindien au Mexique, Tesis de Doctorado, Universidad de París 8, 2003.

4

Una fiesta feliz es lo que Isambert llama una "fiesta lograda (une fête réussie), una institución generadora de espontaneidad» (François-André Isambert, Le sens su sacré. Fête et religion populaire, París, Editions du Minuit, 1982, pág. 157). Si se adopta el concepto "eficacia simbólica» de Lévi-Strauss podría decirse que una fiesta feliz es aquella que cumple esta función de «inducir una transformación», a través de una atribución de sentido, de una estructura (la narración mítica) hacia otra (la cura chamánica) (Claude LéviStrauss, Anthropologie structurale, París, Plon-Pocket, 1974, pág. 231). El problema es que, en la perspectiva levistrausiana, esta arribución de sentido opera a nivel de la expresión verbal, pues se funda necesariamente en un mito o un tema conocido por todos. Para otros autores en cambio, ésta opera a nivel de la acción misma. Las acciones significan por el hecho de $y$ en el momento mismo de ser realizadas. En ciertos contextos rituales y festivos, incluso las palabras ejercen esta función performativa o realizativa (significan algo por el hecho de ser proferidas). La felicidad proviene de la evaluación que se hace al desempeño de la fiesta. Pero esta "evaluación no se hace en función de su validez, sino en términos de su adecuación y relevancia institucional o cultural; la evaluación descansa en la "felicidad» o "infelicidad» de su realización, en el sentido propuesto por Austin» (Rodrigo Díaz Cruz, Archipiélagos de rituales, teorías antropológicas del rifual, Barcelona, Anthropos, 1998, pág. 226).

5 Roger, Caillois, L'homme et le sacré, París, Gallimard, 1976.

La fiesta verdadera: ¿una realización feliz en el teatro? Luces y sombras de los encuentros de teatro comunitario en México ELIZABETH ARAIZA HERNÁNDEZ 


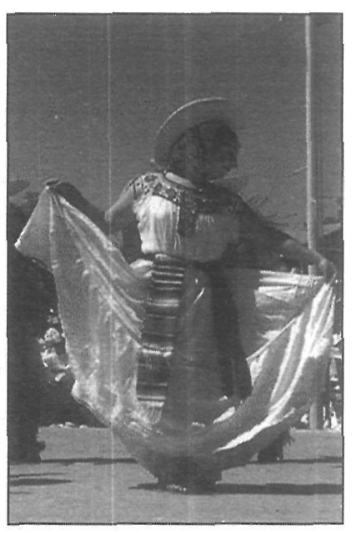

Muchacha en un Baile de rubios de Juxtlahuaca.

6

Citado por Marlène Albert-Llorca, «Regards anthropologiques sur la fête», Parcours, les cahiers du GREP-MP, 2001-2002, núm. 25/26 (www.grep-mp.org) pág. 2.

7

Isambert, op. cit., págs. 125163.

La fiesta verdadera: ¡una realización feliz en el teatro? Luces y sombras de los encuentros de teatro comunitario en México

ELIZABETH

ARAIZA HERNÁNDEZ a un abandono sin control hacia los impulsos mas irreflexivos, a la dilapidación y a la destrucción de las riquezas acumuladas gracias al trabajo cotidiano, al exceso de comida, de bebidas, de ruidos, de sexualidad y de violencia» ${ }^{6}$ Si la prohibición, alimenticia, sexual, social o política, que pesa en lo cotidiano queda suspendida en la fiesta, es con objeto de que se cumpla la función primordial de ésta, que es la de restaurar el desorden original, de tal modo que la naturaleza y la sociedad puedan así ser regeneradas. Se puede apreciar cómo esta concepción conduce hacia el precipicio del universalismo, desde el momento en que erige como modelo un tipo de fiesta.

La crítica que algunos autores han hecho a esta visión universalista reveló la existencia de acciones que, aunque comprometan a la sociedad entera, no ostentan estos aspectos, sino más bien un carácter solemne, recatado, no-excesivo, y ordenado. Es decir, que hay otros modelos posibles de fiesta y que no hay razón de erigir uno de ellos como el bastón de medida. Esta postura sin embargo condujo a otro precipicio: el del relativismo. Ahora bien, el inconveniente de éste es que impide determinar qué es una fiesta ante la imposibilidad de comparar una con otra. Al final de cuentas todas son igualmente válidas, resulta imposible construir un juicio crítico.

A este respecto, parto del principio que se puede hacer una interpretación de los encuentros de Teatro Comunitario en términos de fiesta, sin que se tenga que recurrir a este concepto dominante inspirado por Caillois y $\sin$ que se tenga que incurrir en una postura relativista. Para evitar una proyección de la fiesta anhelada sobre la vivida, de la fiesta primitiva sobre la real, para no caer en la posición según la cual resulta imposible juzgar el carácter feliz o no feliz de la fiesta, se tiene que partir de un criterio mínimo de identificación. Según mi modo de ver, la clave para superar esta dificultad de proyección se encuentra en la lectura sociológica que hace Isambert, expuesta en los capítulos 1 y 2 de la segunda parte intitulada, «La fiesta» .

Por último, es necesario precisar que la interpretación que aquí presento se apoya en un trabajo de observación directa llevado a cabo durante varios años (1992-2000), en diversos poblados, en varias situaciones de representación y en numerosas conversaciones con las personas que participan en estos eventos: organizadores, actores, espectadores y habitantes de las comunidades en donde se lleva a cabo.

\section{LAS FIESTAS DE TEATRO COMUNI- TARIO}

La convergencia principal de los grupos que integran la asociación de teatro comunitario sucede una vez por año. Los primeros nueve encuentros fueron convocados bajo el título sugestivo de Fiesta Regional o bien Fiesta Nacional, según el caso. Más recientemente, las convocatorias a nivel regional adoptan el apelativo de «festival», o simplemente de «Encuentro de Teatro Comunitario». Aunque tienda a abandonarse el término, estos encuentros reproducen el mismo esquema general de las primeras Fiestas. Las primeras Fiestas Regionales estaban regidas por un principio según el cual la Fiesta Nacional debería constituir algo así como un crisol representativo de las obras teatrales mejor logradas a nivel regional. A partir de un proceso de selección, se determinaba cual de los grupos que nacen y trabajan en la región concernida merecía acudir a la fiesta nacional como digno representante de la misma. Sin embargo, con el paso del tiempo este principio se ha ido modificando. La lógica que rige la participación de los grupos, tanto a nivel regional como nacional, suele ser menos clara hoy en día. El criterio más evidente es la integración de los grupos y de las personas invitadas a la fiesta o el encuentro en una red de relaciones interpersonales e interinstitucionales. Con más frecuencia, estos encuentros se asemejan a una confluencia fortuita, circunstancial, de personas con motivaciones diversas, con proyectos variados, tanto profesionales como de vida.

A las fiestas de teatro comunitario asisten artistas proveniente de diferentes sectores de la sociedad mexicana: indígenas, campesinos, estudiantes, obreros, amas de casa. Tanto miembros de las clases populares y medias como altas, ya sea rurales o urbanas. Asisten actores de distintas edades (niños, adolescentes, jóvenes, adultos y ancianos) y sexos (masculino y femenino), cuya actividad se despliega en una asombrosa diversidad de medios: teatro profesional, teatro universitario, casa de la cultura, iglesia, barrios, calle (como el teatro de los niños de la calle o los «chavos banda»). En las fiestas del teatro comunitario se presentan tanto obras teatrales del repertorio universal como creaciones originales; obras interpretadas por artistas profesionales o por «amateurs». Se presentan también danzas y rituales indígenas, «performances» posmodernos y teatro de marionetas o de guiñol al lado de «las obras de la iglesia», y prácticas de 
curación al lado de representaciones relativas a la vida cotidiana en el medio rural o en el urbano, tanto indígena como mestizo.

Ante esta gama asombrosamente amplia y diversa de grupos y producciones teatrales, siempre surge la sospecha de qué es lo que los puede unificar. Se impone por sí misma la pregunta de en qué medida hay una coherencia en todo esto. Por ejemplo, en qué medida no se trata simplemente de un festival de teatro, que se distingue apenas en algún aspecto de aquellos que no son del teatro comunitario. Una serie de acciones y sobre todo un discurso enfático del sentido que debe atribuirse a esas acciones van a establecer la diferencia respecto a un festival teatral cualquiera. Como podrá apreciarse, estas acciones y estos discursos defienden implícitamente una concepción de fiesta, similar a la de Caillois. En el fondo, la fiesta anhelada por los miembros de la asociación de teatro comunitario corresponde con la vivida en el medio indígena. Esta a su vez es asimilada de facto con la idea de «fiesta primitiva» según la fórmula de Callois.

Aunque suelan llevarse a cabo durante el período de vacaciones de verano (entre junio y septiembre), estas fiestas no disponen de una fecha fija. Por regla general, no disponen tampoco de un lugar fijo, pues el pueblo o la ciudad en que se celebran cambia cada vez. La Fiesta regional dura en promedio tres días, en tanto que la nacional suele abarcar entre cinco y seis días. La regional suele llevarse a cabo en pueblos pequeños, en tanto que la nacional se realiza en la capital del estado o bien en la cabecera municipal o en la ciudad más importante de la región concernida. El grupo teatral que habita y trabaja en ese lugar se propone $y$, de ser aceptado, asume las tareas organizativas de la Fiesta. Si bien el programa de actividades es singular en cada encuentro, se puede identificar algo como una trama general presente en todos ellos.

\section{LAS TRES FASES CONSTITUTIIVAS DEL ENCUENTRO DE TEATRO CO- MUNITARIO}

Estos encuentros presentan por lo general tres fases: una fase propiamente teatral, que se realiza cada día por la tarde durante el tiempo que dura la fiesta; una festiva, que marca el inicio y la clausura del evento, y una última que puede ser caracterizada como de organización, de redefinición y de promoción que se lleva a cabo cada día por las mañanas.
Son estas dos últimas las que marcarían una diferencia respecto de cualquier festival de teatro.

La fase teatral se realiza al modo de los festivales: se presentan entre tres y cinco obras teatrales, precediendo cada una un discurso de presentación por parte de un maestro de ceremonias. Incluso la construcción del espacio teatral reproduce la lógica de delimitación y de separación de los teatros de sala. Aunque se realice al aire libre, los límites entre el espacio del público y el espacio de los actores, así como entre un adentro y un afuera del evento teatral, quedan bien delimitados. Con frecuencia se hace uso de límites materiales pero también de una línea imaginaria.

La segunda fase queda marcada por la realización de talleres en los que, por lo general, se hacen ejercicios de expresión teatral o de improvisación, aunque también se hacen trabajos de pintura, escultura, decoración, construcción y manipulación de marionetas. Más que responder a un proyecto o a un programa preconcebidos, estas actividades suelen organizarse en el momento mismo aprovechando los recursos humanos y materiales con los que se cuenta en cada fiesta, de tal modo que los contenidos de esta fase resultan ser siempre singulares. En esta fase suelen realizarse reuniones o asambleas, seminarios o coloquios (con la participación de investigadores universitarios), en donde se redefinen las instancias organizativas del próximo encuentro, se eligen o reeligen los representantes de la asociación, se incluyen nuevos miembros, se establecen compromisos, se elaboran nuevos proyectos y se discuten los métodos de trabajo teatral. Es el momento en que se evalúan las acciones anteriores y se proyecta el futuro del teatro comunitario. Para los representantes de la asociación este momento constituye una suerte de hito, un lugar propicio para hacer visible el rol social y el estatuto que cada quien ocupa en la estructura del teatro comunitario.

Las acciones que marcan el inicio y la clausura del encuentro teatral pueden ser consideradas como la tercera fase. Aunque se realicen en tiempos diferentes presentan prácticamente las mismas características, lo cual autoriza a considerarlas como una sola fase. La clausura se distingue, sin embargo, por la entrega solemne de constancias de asistencia a los actores y de agradecimiento a las personas que ocupan un rango institucional. El primer día por la tarde, suele realizarse un desfile que parte de las afueras del pueblo

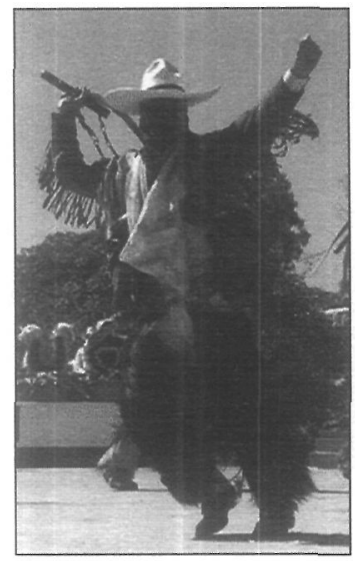

Muchacho en un Baile de rubios de Juxtlahuaca.
La fiesta verdadera: ¿una realización feliz en el teatro? Luces y sombras de los encuentros de teatro comunitario en México ELIZABETH ARAIZA HERNÁNDEZ 


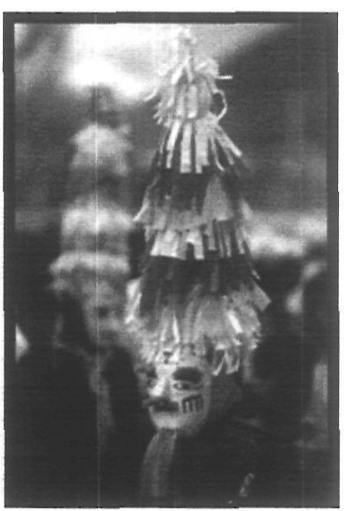

Danzante de Zitlala. y culmina en el espacio teatral, situado éste por lo regular en la plaza central, el zócalo o centro. Se invita a las autoridades del pueblo o de la ciudad para abrir el cortejo, la banda de música local imprime bullicio y alegría a los contingentes que le siguen, conformados éstos por todos los actores que avanzan alegremente llevando sus respectivos vestuarios. En ocasiones, se suman al cortejo grupos de danzantes locales, ejecutando con brío danzas tradicionales. El bullicio y la alegría se hacen aún más patentes con los fuegos artificiales que aporta en ocasiones la comunidad, así como los objetos vistosos que simbolizan la fiesta local. Por ejemplo, en Oaxaca, grandes y vistosas marmotas suntuosamente adornadas acompañaron el desfile de la fiesta nacional de teatro comunitario. Numerosos grupos de danzantes con su vestuario multicolor ejecutaron impresionantes pasos con lo que lograron imprimir a la fiesta regional de Juxtlahuaca un tono y una forma singulares. En Yucatán, estos encuentros suelen inaugurarse con la ejecución de la jarana, incluyendo tanto el suntuoso vestuario de los danzantes como los estandartes y demás símbolos de esta tradición maya-yucateca. Suele integrarse igualmente alguno de los rituales característicos del lugar donde se realiza la fiesta. En Zitlala, Guerrero, el programa teatral fue precedido por una ceremonia de limpia a los participantes, realizada por un curandero local. En San Juan Tabàa, el conjunto de visitantes (actores, miembros asociados, representantes de instituciones de gobierno) llevaron a cabo acciones muy solemnes para ritualizar la petición ante el consejo de ancianos de realizar el encuentro teatral en ese pueblo.

Para envolver este encuentro teatral con un manto de fiesta, se incurre, sobre todo durante la tercera fase, en una apropiación de los signos locales. Pero no se trata de incluir cualquier signo por el hecho de ser festivo, sino que se eligen aquellos que simbolizan la fiesta «verdadera», la fiesta bien lograda, es decir la fiesta patronal, que por ende es la indígena. $\mathrm{Si}$ estos encuentros se realizan en regiones caracterizadas por un alto índice de población indígena, no es tanto porque los indígenas constituyan una mayoría en la asociación o en los encuentros, sino porque aparecen, en la óptica de los promotores teatrales, como la norma de la festividad. Todo sucede como si el medio indígena comportara por sí mismo esta esencia festiva, y que bastara con realizar ahí las actividades teatrales para que ellas adquirieran este halo de festividad verdadera.
Es como si los objetos que se encuentran ahí estuvieran en sí mismos cargados de una ritualidad, de una sacralidad y de una festividad esenciales, como si fuera suficiente estar ahí para lograr un acceso inmediato.

Con todo, ha habido fiestas de teatro comunitario que, aunque se lleven a cabo en el medio indígena, se desenvuelven en un ambiente no sólo solemne sino incluso triste, no sólo sobrio sino monótono. Un ambiente más cercano a la indiferencia y a la apatía que emana por igual de los actores, de los espectadores y de los lugareños. Pero también ha habido fiestas que aunque se realicen en poblados mestizos o urbanos vieron materializar este ideal de fiesta verdadera, «la fiesta primitiva». Éstas se caracterizaron por una cierta exuberancia, una alegría desbordada, un despilfarro de energía expresada en gestos y movimientos, una ostentación de símbolos auditivos, sensoriales, gustativos. Lo cual indica que en los encuentros de teatro comunitario la fiesta no siempre se logra bien. $O$ si se quiere, no siempre hay un logro feliz y eficaz de la concepción de fiesta en tanto que exuberancia, exceso de toda suerte, subversión del orden establecido, desorden exacerbado, alegría y bullicio estridentes. Porque se puede argumentar, en favor de éstos, que existen otros modelos de fiesta.

Si se apela al concepto de fiesta en su sentido solemne, de orden y de control, se concluirá sin duda que sí hay aquí una realización feliz de la misma. Podría decirse que estos encuentros pueden suscitar tanto este modelo como aquel de exuberancia, desorden y exceso. Incluso se pueden traer a colación datos etnográficos que ponen de manifiesto la existencia de fiestas indígenas que no presentan las características de la fiesta primitiva. Baste evocar, como prueba, la discreción, la solemnidad, la lentitud que suelen adquirir los bailes (expresión espontánea de la alegría en pareja siguiendo el ritmo de la música) e incluso la danza (grupos organizados expresamente). A menudo, éstos dan la impresión de que no «pasa de ser un digno frotar de los pies en el suelo, [una ausencia de] pasos brillantes». Esta perturbadora impresión se disipa tan pronto como se repara en la preocupación esencial que motiva tanto al danzante como a los espectadores miembros de la comunidad indígena: las obligaciones sagradas de los ejecutantes. Comprendemos entonces que: "la falta de pasos brillantes sólo sirve para subrayar que es el simple acto de la ejecución lo que designa a alguien como poseedor de 
una posición poderosa, junto con el atavío del danzante y los objetos que éste empuña durante la danza» ${ }^{8}$.

Lo anterior autorizaría a afirmar que los encuentros que se desenvuelven según el modelo ordenado no contradicen, sino que reafirman, ese ideal de fiesta indígena del teatro comunitario. También podría subrayarse la función de algunas fiestas de instaurar un estatuto social, de comunicar el lugar que cada quién ocupa en la jerarquía social, es decir, de preservar un orden social. Así se enfatiza al mismo tiempo la existencia de este tipo de fiestas en el medio indígena. El riesgo de este razonamiento es que conduce a un relativismo conformista incapaz de ejercer una reflexión crítica. En consecuencia, habría que reparar en un aspecto importante de la fiesta, independientemente del modelo bajo el cual se desenvuelva, el que atañe a la sociedad entera. Estos encuentros, en cambio, siguen concerniendo a un grupo reducido de personas, a lo sumo el conjunto de los visitantes, más comúnmente a los representantes de esta asociación teatral. Si de instaurar un orden se trata, es el de la asociación, mas no el de todos los participantes. Ahora bien, no se trata aquí tanto de determinar qué tipo de fiesta realiza el teatro comunitario como de averiguar por qué el concepto de fiesta que éste transmite no siempre se realiza felizmente. ¿A qué se debe que, a pesar de los esfuerzos de los organizadores de tejer un ropaje de fiesta con el cual envolver estos encuentros, los espectadores locales se queden seguido con la impresión de ser simples testigos, de asistir a una especie de acto obligado, ajeno, impuesto desde afuera y desde arriba? La expresión que usan a veces los zapotecos de Oaxaca para referirse a la fiesta de teatro comunitario, resulta bastante reveladora a este respecto: "la fiesta del gobierno", a la cual oponen la «costumbre», es decir, la fiesta patronal, la indígena.

¿En qué medida dicha variación puede atribuirse exclusivamente a uno o a un conjunto de factores? Se pueden dar varios tipos de situaciones determinantes, como la capacidad de construir una amplia red de relaciones interpersonales e interinstitucionales por parte de los miembros de esta asociación teatral, o bien el arraigo de la actividad teatral en el pueblo donde se lleva a cabo la fiesta de teatro; incluso el grado de simpatía y de reconocimiento de que gozan el grupo teatral y los actores en la población que acoge el encuentro. El tamaño del pueblo puede asimismo incidir: las comunidades con población reducida serían, tal vez, más propicias a la convivencia y a la reciprocidad entre visitantes y lugareños. En consecuencia, podría decirse que la Fiesta regional es más propicia para la festividad que la nacional. Puede ser que se trate simplemente del grado de elaboración de las obras teatrales y de los espectáculos que se presentan a lo largo de la fiesta. A mayor calidad de las producciones teatrales correspondería una respuesta más entusiasta y más participativa de parte de los espectadores. Se puede atribuir al temperamento diferenciado de los lugareños: los mestizos o los campesinos serían, quizá, más dados a la espontaneidad y a la participación activa y directa, mientras que los indígenas serían más reservados, discretos y reacios al contacto con los visitantes. Se trata tal vez, de un proceso involutivo según en cual las fiestas más recientes serían menos festivas que las primeras. O bien, al contrario, de un proceso evolutivo, hacia una festividad cada vez mejor lograda.

Según mi modo de ver, la definición que sugiere Isambert resulta suficientemente restringida como para no sucumbir a la tentación relativista, pero también suficientemente abierta como para no erigirla en modelo, cediendo al universalismo. Se presenta entonces como un argumento convincente para responder a las interrogantes arriba planteadas. Para Isambert una fiesta es:

...primero que nada un acto colectivo. La fiesta se rodea de representaciones, de imágenes materiales o mentales, pero éstas no figuran sino como acompañantes del elemento activo. Se diría lo mismo de los diversos objetos materiales, decoración, alimentos, etc. que sirven para la acción de la fiesta. En segundo lugar, la fiesta es total o por lo menos completa, pues pone en juego varios registros de la vida social. En esto, la noción de fiesta, desborda, la noción de rito e incluso la de ceremonia, secuencia de ritos. Por último, esta acción es simbólica, en el sentido de que evoca un ser, una colectividad...La acción propia de la fiesta es la simbolización [...]; para que el símbolo sea reconocible tiene que ser relativamente fijo?.

Lo anterior me conduce a sostener que es justamente la ausencia de una fecha fija y de un lugar fijo lo que produce una variabilidad en los encuentros de teatro comunitario. De alguna manera, el mayor éxito de estas fiestas es al mismo tiempo su mayor fracaso, a saber, la movilidad espacial y temporal. La ausencia de una fecha fija y de un lugar fijo impide que se cumpla esta condición de simbolización

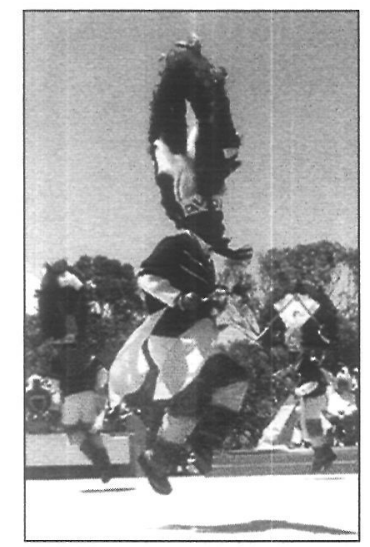

Danza de la pluma. Oaxaca.

8

David Freidel et al., El cosmos maya. Tres mil años por la senda de los chamanes, México, FCE, 1999, pág. 267.

9 Isambert, op. cit., págs. 160161.

La fiesta verdadera: ¿una realización feliz en el teatro? Luces y sombras de los encuentros de teatro comunitario en México ELIZABETH ARAIZA HERNÁNDEZ 
11

Ibid., pág. 35 .

12

Goffman citado por Clifford Geertz en La inferpretación de las culturas, Barcelona, Gedisa, 1989 , pág. 348.
La fiesta verdadera: ¿una realización feliz en el teatro? Luces y sombras de los encuentros de teatro comunitario en México

ELIZABETH

ARAIZA HERNÁNDEZ que es constitutiva de toda fiesta. Subrayar la necesidad de una relativa estabilidad de los símbolos para que puedan simbolizar no implica prejuzgar la validez de sus contenidos, de su carácter ordenado o desordenado, subversivo o preservador del orden establecido, alocado o sosegado, exuberante o sobrio.

Las estrategias de la asociación de teatro comunitario para hacer de los encuentros una fiesta verdadera, consistentes por ejemplo en la adopción de un rebozo, o en la recreación de la calenda, pueden cobrar un sentido de ritualidad y de festividad en un pueblo de la sierra, pero no en uno de la costa. El rebozo no se usa en la costa y la calenda no es tradición ahí. Este tipo de estrategias apuntan a la imposición de un modelo que se supone tendría que funcionar de igual manera en cada pueblo. Ahora bien, el comportamiento festivo no se decreta. No hay cosa, persona, lugar que sea por esencia sagrado, festivo o ritual, pero cualquier elemento de la naturaleza, lugar, persona o cosa pueden devenir sagrados. Para que esto suceda, se necesita una practica habitual, una continuidad, una relativa estabilidad de los símbolos. Es a través del uso que un signo adquiere un contenido sagrado. La ritualidad en la fiesta «no es una cosa, sino una relación de los hombres con las cosas y con las personas» ${ }^{10}$. Ningún grupo social posee la capacidad exclusiva de suscitar un comportamiento festivo.

La actividad teatral puede suscitar un ambiente festivo tanto en una comunidad indígena como en un pueblo mestizo, en un barrio pobre de la ciudad como en una colonia clase media. Para que esto suceda, para que la fiesta de teatro se vuelva una celebración colectiva, que concierna a todos por igual, tanto a los habitantes de la comunidad donde se realiza como a los organizadores y a los actores, se necesita una práctica habitual, se requiere que los símbolos que ésta intenta instituir gocen de una relativa fijación. Como nos hace ver Gruau a partir de un comentario de Paul Claudel: «Rien n'est sacré que ce que nous consacrons, que ce que nous sacralisons»11. Se podría decir que los encuentros de teatro comunitario andan en busca de un lenguaje; en esto reside su ineficacia relativa, porque la estabilidad de tal lenguaje implica compartir un modo de vida, en este caso la de los habitantes de las comunidades en donde éstos se llevan a cabo. Pero, dado que la sede de la fiesta cambia todo el tiempo, que no hay una fecha precisa y que los símbolos no son compartidos por todos, no se cumple esta condición.
La participación más o menos asidua permite a un grupo reducido de gente de teatro y de promotores teatrales atribuir un sentido a cada una de las acciones, a cada uno de los objetos, a cada uno de los discursos constitutivos de la fiesta. De tal modo, estos encuentros establecen, sin proponérselo tal vez, una distinción entre un grupo reducido que logra alcanzar una visión de continuidad y otro mucho más numeroso para quien esta visión no puede ser sino discontinua. Esta visión de discontinuidad les impide compartir el mismo sentido de fiesta, de celebración. La mayoría de los asistentes se queda con la impresión de asistir como testigos o invitados a lo que ese grupo reducido celebra, instaura, ordena, sacraliza o bien desordena, subvierte, despilfarra y critica. Para que la fiesta de teatro comunitario deje de ser percibida por la mayoría de asistentes como un proceso discontinuo, un acto particular que sólo se vive una sola vez, algo que viene de fuera, que es externo a la comunidad e incluso ajeno, se necesita no sólo la capacidad organizativa de los promotores, la calidad estética de la propuesta teatral o la cantidad de grupos, se requiere un arraigo, una cierta estabilidad de los símbolos.

Si los encuentros de teatro comunitario logran en ocasiones realizar una fiesta feliz, a pesar de la ausencia de una fijeza de los símbolos, se debe precisamente a su carácter situacional. Esto se hace posible cuando la actividad teatral adopta la dinámica social y cultural del lugar en donde se realiza. Cuando el conjunto de las personas que se encuentran están en disposición de entregarse por completo a esta misma actividad, sin tener otra razón, sin querer imponer un modelo de fiesta, sino dejarse llevar por ese flujo común que emerge de la situación. Para abreviar, es cuando esos encuentros son simplemente una «reunión focalizada», es decir,

...un conjunto de personas entregadas a un flujo común de actividad y relacionadas entre sí en razón de ese flujo [...] Esas reuniones se forman y se dispersan; sus participantes fluctúan; la actividad que los concentra es un proceso singular, particular, que se repite de cuando en cuando en lugar de ser un proceso continuo. Dichas reuniones toman su forma de la situación que las suscita, del suelo en que están situadas $^{12}$.

Se puede apreciar la dificultad que enfrentan los grupos teatrales en su lucha por cautivar la atención de un público masivo y 
diverso. La dificultad es mayor todavía para aquellos que decidieron abandonar el lugar, de alguna manera, confortable de la sala con su público cautivo y fiel aunque reducido en cantidad. Es esta la luz a que refiere el título del presente artículo. Salir a la calle, presentarse al aire libre, adentrarse en pueblos poco habituados al teatro, exige un trabajo de experimentación constante con tal de encontrar los modos de organzación social, de creación y de difusión acordes a cada uno de los grupos sociales que se pasean por las calles o al aire libre y que habitan en los pueblos. Veamos ahora las sombras. El dilema del teatro comuntario parece ser el siguiente : asumir que los encuentros a los que convoca son una reunión focalizada, esto es, una cuya realización es fortuita y circunstancial, pero feliz, o bien seguir insistiendo en imponer el modelo de la fiesta indígena, aunque su realización resulte casi siempre poco feliz. Podemos admitir que el teatro es una práctica universal, pero hay que reconocer que los modos en que se ésta instituye, varian de una sociedad a otra, de un pueblo a otro, de una cultura a otra.

\section{BIBLIOGRAFÍA}

Araiza Hernández, Elizabeth, Sous le signe de "l'entre deux» Anthropologie du théâtre amérindien au Mexique, tesis de doctorado, Universidad de París 8, 2003.

Albert-Llorca, Marlène, «Regards anthropologiques sur la fête», Parcours, les ca- biers du GREP-MP, 2001-2002, $N^{\circ} 25 / 26$, (www.grep-mp.org).

Caillois, Roger, L'homme et le sacré, París, Gallimard, 1976.

Díaz Cruz, Rodrigo, Archipiélagos de rituales, teorías antropológicas del ritual, Barcelona, Anthropos, 1998.

Freidel, David, Schele, Linda, y Parker, Joy, El cosmos maya. Tres mil años por la senda de los chamanes, México, Fondo de Cultura Económica, 1999.

Frischman, Donald, El nuevo teatro popular en México, México, CITRU-INBA, 1990.

Geertz, Clifford, La interpretación de las culturas, Barcelona, Gedisa, 1989.

Grimes, Ronald L., Simbolo y conquista. Rituales y teatro en Santa Fé, Nuevo México, México, Fondo de Cultura Económica, 1981.

Gouhier, Henri, L'essence du théatre, París, Aubier-Montaigne, "Présence et pensée», núm. 11, 1968.

Gruau, Maurice, L'bomme rituel, París, Métailié, 1999.

Isambert, François-André, Le sens su sacré. Fête et religion populaire, París, Editions du Minuit, 1982.

Lévi-Strauss, Claude, Anthropologie structurale, París, Plon-Pocket, 1974.

Rosales Ayala, Héctor, Tlaltenango: las transformaciones del sentido de una fiesta popular, México, UNAM-CRIM, 1988.

Versényi, Adam, El teatro en América Latina, Nueva York, Cambridge University Press, 1996.
Ia fiesta verdadera: juna reali-

zación feliz en el teatro? Luces y sombras de los encuentros de teatro comunitario en México

ELIZABETH

ARAIZA HERNANDEZ 